\title{
Clinical and Pathological Findings of Fatal 2009-2010 Pandemic Influenza A (H1N1) Infection in Estonia
}

\author{
Kadri Tamme ${ }^{1}$, Ave Minajeva ${ }^{2,3}$, Vivika Adamson ${ }^{4}$, Kaarina Ristmägi ${ }^{5}$, \\ Jaak Põder ${ }^{5}$, Irja Lutsar ${ }^{6}$ \\ ${ }^{1}$ Anaesthesiology and Intensive Care Clinic, Tartu University Hospital, Tartu, Estonia, ${ }^{2}$ Institute of Pathological \\ Anatomy and Forensic Medicine, University of Tartu, Tartu, Estonia, ${ }^{3}$ Institute of Clinical Medicine, Tallinn University \\ of Technology, Tallinn, Estonia, ${ }^{4}$ Infection Control Department, Tartu University Hospital, Tartu, Estonia, \\ ${ }^{5}$ Estonian Forensic Science Institute, Tallinn, Estonia, ${ }^{6}$ Department of Microbiology, University of Tartu, Tartu, Estonia
}

Key words: influenza A (H1N1); fatal influenza; pathological findings; antiviral therapy.

Summary. The aim of this study was to analyze all deaths from A (H1N1) in Estonia during the 2009-2010 epidemic to find out the reasons of high mortality and optimize management strategies for future influenza epidemics.

Material and Methods. A retrospective review of medical records, autopsy reports, and reassessment of autopsy slides of all fatal cases of proven A (H1N1) influenza in Estonia from October 2009 to May 2010 was carried out.

Results. There were a total of 21 proven fatal cases (median age, 57 years); the population mortality rate of 1.56 per 100000 inhabitants was one of the highest in the world. Altogether, 18 of the 21 patients had known risk factors for influenza, and 3 patients were previously healthy children. Three decedents had received antiviral treatment, and none had been immunized. There were 19 decedents autopsied, with viral pneumonia (58\%) being the most frequent pathological finding; $40 \%$ had evidence of bacterial superinfection. In 4 cases, influenza was not clinically suspected and was diagnosed postmortem. Influenza was the primary cause of death in 15 decedents, while in 9 cases, comorbidities played a significant role in fatal outcome. In the remaining 4 cases, another illness was considered the primary cause of death with influenza as an accompanying factor.

Conclusions. High autopsy rate and liberal postmortem PCR testing enables the detection of additional A (H1N1) influenza cases, yet it might lead to overestimation of the population mortality rates, especially in a small population with low number of events. Increased vaccine coverage, vigilant diagnosing including wide PCR testing, and early more liberal use of antiviral medications during the influenza A (H1N1) epidemic may hold the potential of lowering population mortality.

\section{Introduction}

In March 2009, a novel influenza virus subtype A (H1N1) was identified in patients in Mexico and the United States. The virus was a genetic reassortant of two preexisting swine influenza virus lineages (1). During the spring of 2009, an outbreak spread globally, and in June 2009, the World Health Organization signaled that a novel A (H1N1) influenza pandemic was under way (2).

Reports from several countries demonstrated mostly a benign course of the disease with the mortality rate of $<1 \%$ (3) and pointed out that $75 \%-$ $98 \%$ of patients had comorbidities or predisposing conditions, notably cardiac and respiratory diseases, immunosuppression, pregnancy, and obesity (3-8). In addition, compared with seasonal influenza, the patient population with pandemic influenza was

Correspondence to K. Tamme, Anaesthesiology and Intensive Care Clinic, Tartu University Hospital, L. Puusepa 8, 51014 Tartu, Estonia. E-mail: kadri.tamme@kliinikum.ee younger $(7,8)$. Autopsy findings, reported in a limited number of cases, did not show any differences between seasonal and pandemic influenza $(5,6,9,10)$.

In Estonia, during the first wave of the pandemic from October 1, 2009, to May 31, 2010, altogether 2294 respiratory samples were tested for the A (H1N1) virus by quantitative reverse transcription-polymerase chain reaction (qRT-PCR), of which $38.4 \%$ were positive (11). Among the 748 cases of the A (H1N1) infection confirmed by qRTPCR, 21 patients $(2.8 \%)$ died, leading to one of the highest population mortality rates in the world (1.56 per 100000 inhabitants) (11). At the same time, the immunization rate was one of the lowest in $\mathrm{Eu}$ rope with only $2.6 \%$ of the population involved by April 2010 (11). It was not clear from initial reports whether the high mortality was caused by the viral infection alone or there were other contributing factors like exacerbation of concomitant diseases or other risk factors. 
In order to describe the population at risk of death from the 2009 pandemic influenza, to find out the causes of death and the reasons of high mortality, and, based on this, to optimize management strategies for future influenza epidemics, a detailed analysis of all deaths was conducted by reviewing available clinical, pathological, and microbiological data.

\section{Material and Methods}

Setting. In Estonia, all hospital deaths occurring within 24 hours from admission as well as violent deaths and those caused by a suspected or proven acute infection, occurring during pregnancy or delivery or at age below 1 year and/or unsolved medical issues are subject to autopsy (12). In all other cases, the need of autopsy is decided by the treating physician. In 2009, altogether $21.5 \%$ of all deaths were subject to autopsy (13). The autopsy rate for potential deaths due to influenza (cause of death J10-J11 by ICD-10 [14]) was 50\% in 2009 (13).

As influenza reached the epidemic phase in Estonia on November 24, 2009, the Health Board of Estonia issued a circular enforcing sampling for A (H1N1) qRT-PCR testing in all intensive care patients with a clinical suspicion of influenza. In addition, in all autopsy cases with macroscopic evidence of pneumonia, lung tissue specimens or respiratory swabs were also subjected to A (H1N1) testing. Altogether, 58 autopsy samples were tested for A (H1N1) by qRT-PCR with 17 of them showing positive results. All cases of influenza and influenzalike illness (ILI) were reported to the Health Board of Estonia by laboratory staff and/or a diagnosing physician.

Subjects. The medical records and autopsy reports of all 21 fatal cases of the confirmed A (H1N1) influenza in Estonia from October 1, 2009, to May 31, 2010, were retrospectively reviewed. The A (H1N1) influenza was considered confirmed if viral mRNA was detected by qRT-PCR either in nasopharyngeal (NP) swabs, bronchoalveolar lavage fluid, tracheal aspirate, or postmortem lung tissue specimens. Demographic and clinical data were collected from medical records as detailed elsewhere $(3,5,6)$.

Population mortality rates were calculated using population estimates from January 1, 2010, given by Statistics Estonia (15); for calculation of $95 \%$ confidence intervals (CI), Poisson distribution for rare events was used (16).

Pathological and Microbiological Evaluation. All qRT-PCR tests were performed in the Central Laboratory of the Health Board of Estonia according to the protocol of the Centers for Disease Control and Prevention (17). Enzyme-linked immunosorbent assay for antibody determination against influenza A and $\mathrm{B}$, direct immunofluorescence and rapid influenza tests were performed in local hospital laboratories according to the manufacturers' instructions.
Blood cultures were taken when severe sepsis or septic shock was suspected, preferably before initiation of antibiotic treatment. Postmortem lung tissue cultures were taken following sterile techniques only in cases of extensive or necrotizing pneumonia and when time from death to autopsy did not exceed 24 hours. All samples were analyzed in local microbiology laboratories following the guidelines of the Clinical Laboratory and Standards Institute (18).

Routine autopsy examinations were performed by local pathology departments $(n=17)$ or by the Estonian Forensic Science Institute $(\mathrm{n}=2)$, as appropriate. At least two tissue specimens of both lungs and bronchi and one tissue section of the liver, spleen, pancreas, left and right heart, brain, and both kidneys were obtained for histopathological examination. In case of macroscopic evidence of tracheitis, two specimens from trachea were collected. Tissue sections were paraffin-embedded and stained with hematoxylin-eosin. All autopsy protocols and histology slides were re-reviewed by one of the authors (A.M.) with special attention to pulmonary findings.

According to primary causes of death, cases were categorized as follows: group 1, influenza or its complications as the direct cause of death (patients with ILI together with pathological findings characteristic of influenza and/or bacterial superinfection without significant comorbidities); group 2, influenza or its complications and severe underlying disease contributing equally to fatal outcome (patients with severe underlying conditions together with ILI, pathological findings of influenza or bacterial superinfection and of a serious underlying disease); and group 3, influenza as an accompanying factor (patients with another serious disease, with no clinical suspicion of influenza, no or minimal pathological findings characteristic of influenza and other serious potentially fatal medical condition on autopsy).

\section{Results}

Population. Altogether, 21 deaths were reported (Fig. 1). The population mortality rate was 1.56 per 100000 inhabitants (95\% CI, 0.19-5.64) including 1.06 per $100000(95 \%$ CI $0.03-5.91)$ for those aged $\leq 19$ years, 0.98 per 100000 (95\% CI, 0.03-5.46) for those aged between 20 to 64 years, and 4.37 per 100000 (95\% CI, 1.19-11.19) for those aged $\geq 65$ years. A total of 19 decedents underwent autopsy.

As shown in Tables 1 and 2, the study population was predominantly male, with a median age of 57 years (IQR, 31.3 to 69.4); almost half of the patients were older than 65 years and 3 were younger than 19 years. Underlying medical conditions were very common (18 of the 21) with chronic heart disease, chronic liver disease, and diabetes reported most frequently (Table 1). 


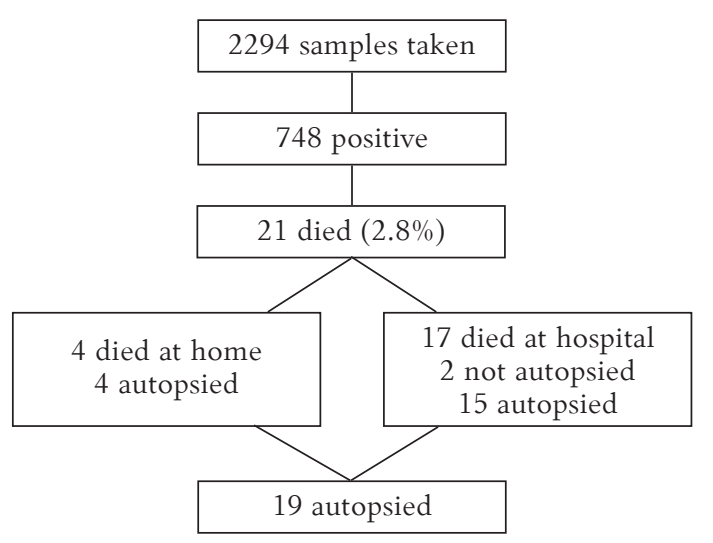

Fig. 1. Flow diagram of qRT-PCR-positive influenza A (H1N1) cases in Estonia during the 2009-2010 influenza season

Table 1. Demographic and Clinical Characteristics of 21 Study Decedents Who Had Confirmed Infection With Novel Influenza A (H1N1) Virus

\begin{tabular}{|c|c|}
\hline Char & Value \\
\hline Age, median (IQR), years & $\begin{array}{c}57 \\
(31.3 ; 69.4) \\
\end{array}$ \\
\hline Male sex, n (\%) & $15(71)$ \\
\hline $\begin{array}{l}\text { rs present, No./total No. } \\
\text { c heart disease } \\
\text { nary artery disease } \\
\text { ertensive heart disease } \\
\text { nic heart failure } \\
\text { c liver disease } \\
\text { es mellitus } \\
\text { losuppression (via disease or treatm } \\
\text { c obstructive pulmonary disease }\end{array}$ & $\begin{array}{l}18 / 21 \\
12 / 21 \\
10 / 21 \\
5 / 21 \\
5 / 21 \\
5 / 21 \\
4 / 21 \\
3 / 21 \\
3 / 21 \\
2 / 21 \\
2 / 21 \\
1 / 21 \\
1 / 21\end{array}$ \\
\hline $\begin{array}{l}\text { f symptoms known } \\
\text { a, and hemoptysis) } \\
\text { niting, and diarrhea) } \\
\text { im) }\end{array}$ & $\begin{array}{l}15 / 17 \\
12 / 17 \\
5 / 17 \\
2 / 17 \\
\end{array}$ \\
\hline Hospitalized, No./total No. & $17 / 21$ \\
\hline & 7 \\
\hline Admitted to ICU, No./total No. & $15 / 21$ \\
\hline No. of positive/No. of taken & $4 / 9$ \\
\hline In vivo qRT-PCR, No. of positive/No. of taken & $4 / 6$ \\
\hline Blood cultures, No. of positive/No. of taken & $3 / 10$ \\
\hline Antiviral therapy, No. of received/total No. & $3 / 21$ \\
\hline Antibacterial therapy, No. of received/total No. & $16 / 21$ \\
\hline Length of stay in ICU, median (IQR), days & $2(1 ; 16)$ \\
\hline Length of stay in hospital, median (IQR), days & $6(1 ; 21.3)$ \\
\hline \multicolumn{2}{|c|}{$\begin{array}{l}\text { *Nosocomial cases excluded. } \\
\text { ELISA, enzyme-linked immunosorbent assay for in vitro de- } \\
\text { termination of antibodies against influenza A and B (Euro- } \\
\text { immune, Germany); IF, direct immunofluorescence test for } \\
\text { detection of influenza A and B (Oxoid, Denmark); IQR, in- } \\
\text { terquartile range; qRT-PCR, quantitative reverse transcription- } \\
\text { polymerase chain reaction; RIDT, rapid influenza diagnostic } \\
\text { test (Certest Biotec, Spain). }\end{array}$} \\
\hline
\end{tabular}

Cough and dyspnea were the most frequent symptoms followed by fever and gastrointestinal signs (Table 1). Two patients with a history of chronic alcohol abuse had no typical influenza symptoms and presented with disturbances of consciousness like delirium or coma (cases 9 and 21). In 4 nosocomial cases, influenza A (H1N1) was diagnosed postmortem after the ICU treatment due to other diseases, namely pneumonia and acute myocardial infarction (MI) (case 7; negative results of qRT-PCR for A [H1N1] on admission), colon carcinoma and postoperative peritonitis (case 10), purulent hip joint infection (case 15), and acute cholecystitis (case 16).

Altogether, 11 of the 21 deaths occurred early: 4 patients died at home and 7 within 24 hours of hospital admission. Of the former 4 patients, 2 never sought medical help (cases 11 and 14), 1 patient was dead when the ambulance arrived (case 2), and 1 refused hospitalization and died 3 days later (case 4).

Microbiological Findings. About half of the decedents (11 of the 21) were tested for influenza A (H1N1) antemortem, and 8 had positive results. Of the 10 patients staying in the ICU for more than one day, intravital PCR testing was performed in 5 and any laboratory influenza testing in 7 patients.

Besides, 9 of the 21 decedents had positive blood cultures and/or autopsy findings consistent with sepsis and/or bacterial pneumonia. Staphylococcus aureus $(\mathrm{n}=5)$ and Streptococcus pneumoniae $(\mathrm{n}=2)$ were the most frequently involved microorganisms. Klebsiella pneumoniae, Escherichia coli, and Candida glabrata were isolated from postmortem lung specimens in one case each (Table 2). In 3 cases $(5,10$, and 15), bacterial infection was not a complication of influenza, but preceded the nosocomial A (H1N1) infection.

Only 3 of the 21 patients received oseltamivir: all in the ICU and 1 within 48 hours from the onset of symptoms. None of the patients had been immunized.

Pathological Findings and Causes of Death. Pathological findings are detailed in Table 3. In 6 cases (group 1; median age, 54 years), the novel influenza A viral infection and/or its immediate complications were the direct cause of death. In 4 of them, acute tracheitis, bronchitis, bronchiolitis, diffuse alveolar damage (DAD) with or without hyaline membrane formation, pulmonary edema, and/or alveolar hemorrhages were found (Fig. 2A). In the remaining 2 cases, pulmonary histopathological findings of influenza were intermingled with signs of bacterial coinfection such as necrotizing bronchiolitis and pneumonia, neutrophil-predominant inflammatory exudates, and formation of microabscesses (Fig. $2 B)$. As shown in Table 3, various pathological findings were seen in other organs, with severe renal tubular necrosis and cerebral edema probably being 
Table 2. Underlying Medical Conditions, Duration of Illness, and Results of Microbiological Tests of 21 Study Decedents (Cases Grouped According to the Primary Cause of Death)

\begin{tabular}{|c|c|c|c|c|c|c|c|c|c|c|}
\hline $\begin{array}{l}\text { Case } \\
\text { No. }\end{array}$ & $\begin{array}{l}\text { Age, } \\
\text { Years/ } \\
\text { Sex }\end{array}$ & $\begin{array}{c}\text { Duration } \\
\text { of Influenza- } \\
\text { Like } \\
\text { Symptoms } \\
\text { Prior } \\
\text { to Death }\end{array}$ & $\begin{array}{l}\text { Underlying Medical } \\
\text { Conditions }\end{array}$ & $\begin{array}{c}\text { Admitted } \\
\text { to } \\
\text { Hospital } \\
\mathrm{Y} / \mathrm{N}\end{array}$ & $\begin{array}{l}\text { ICU } \\
\mathrm{Y} / \mathrm{N}\end{array}$ & $\begin{array}{l}\text { Length of } \\
\text { Hospitaliza- } \\
\text { tion, Days }\end{array}$ & $\begin{array}{l}\text { Influenza } \\
\text { Testing/ } \\
\text { Result }\end{array}$ & $\begin{array}{l}\text { H1N1 } \\
\text { PCR } \\
\text { Premor- } \\
\text { tem (1) } \\
\text { or Post- } \\
\text { mortem } \\
\text { (2) }\end{array}$ & $\begin{array}{l}\text { Results of In } \\
\text { Vivo Blood } \\
\text { and } \\
\text { Postmortem } \\
\text { Lung Tissue } \\
\text { Cultures }\end{array}$ & $\begin{array}{c}\text { Anti- } \\
\text { bacterial } \\
\text { Therapy } \\
\text { Y/N }\end{array}$ \\
\hline
\end{tabular}

Group 1 - death due to influenza or its complications (bacterial superinfection)

\begin{tabular}{ccccccccccc}
\hline 1 & $14 / \mathrm{M}$ & 4 & None & $\mathrm{Y}$ & $\mathrm{Y}$ & 1 & $\mathrm{RIDT} /-$ & 2 & - & $\mathrm{Y}$ \\
\hline 2 & $52 / \mathrm{M}$ & 3 & $\mathrm{CAD}$ & $\mathrm{N}$ & $\mathrm{NA}$ & $\mathrm{NA}$ & $\mathrm{ND}$ & 2 & $\mathrm{ND}$ & $\mathrm{N}$ \\
\hline 11 & $31 / \mathrm{F}$ & 7 & $\begin{array}{c}\text { DM, 12-week } \\
\text { pregnancy, epilepsy }\end{array}$ & $\mathrm{N}$ & $\mathrm{NA}$ & $\mathrm{NA}$ & $\mathrm{ND}$ & 2 & $\mathrm{ND}$ & $\mathrm{N}$ \\
\hline $13^{*}$ & $15 / \mathrm{M}$ & 4 & None & $\mathrm{Y}$ & $\mathrm{Y}$ & 3 & $\mathrm{RIDT} /+$ & 2 & $\begin{array}{c}\text { S. aureus } \\
\text { (postmortem) }\end{array}$ \\
\hline 19 & $3 / \mathrm{F}$ & 4 & None & $\mathrm{Y}$ & $\mathrm{Y}$ & 1 & $\mathrm{Y}$ & 2 & $\begin{array}{c}\text { S. aureus, } \\
\text { S. pneumoniae } \\
\text { (postmortem) }\end{array}$ \\
\hline 21 & $50 / \mathrm{F}$ & Unknown & CAA, ALD & $\mathrm{Y}$ & $\mathrm{Y}$ & 1 & $\mathrm{IF} /+$ & 2 & $\mathrm{ND}$ & $\mathrm{Y}$
\end{tabular}

Group 2 - death due to influenza or its complications with severe underlying disease contributing to fatal outcome

\begin{tabular}{|c|c|c|c|c|c|c|c|c|c|c|}
\hline 3 & $58 / \mathrm{M}$ & 2 & $\begin{array}{l}\text { DM, CAD, hemolytic } \\
\text { anemia, immunosup- } \\
\text { pression due to high- } \\
\text { dose corticosteroids }\end{array}$ & $\mathrm{Y}$ & $\mathrm{Y}$ & 1 & $\mathrm{IF} /-$ & 2 & $\begin{array}{c}\text { Klebsiella } \\
\text { pneumoniae } \\
\text { (postmortem) }\end{array}$ & $\mathrm{Y}$ \\
\hline 4 & $69 / \mathrm{M}$ & 8 & $\mathrm{CAD}, \mathrm{CHF}$, & $\mathrm{N}$ & NA & NA & ND & 2 & ND & $\mathrm{Y}$ \\
\hline 6 & $75 / \mathrm{M}$ & 2 & $\begin{array}{l}\text { HTN, CAD, CHF, } \\
\text { chronic pyelonephri- } \\
\text { tis, obesity }\end{array}$ & $\mathrm{Y}$ & $\mathrm{Y}$ & 1 & ELISA/- & 1 & $\begin{array}{l}\text { S. aureus } \\
\text { (blood) }\end{array}$ & $\mathrm{Y}$ \\
\hline 8 & $68 / \mathrm{M}$ & 28 & $\begin{array}{c}\text { COPD. } \\
\text { HTN, CAD, CHF }\end{array}$ & $\mathrm{Y}$ & $\mathrm{Y}$ & 21 & $\mathrm{IF} /+$ & 2 & - (blood) & $\mathrm{Y}$ \\
\hline 9 & $46 / \mathrm{M}$ & 24 & CAD, CAA & $\mathrm{Y}$ & $\mathrm{Y}$ & 23 & $\mathrm{IF} /+$ & 1 & - (blood) & $\mathrm{Y}$ \\
\hline 14 & $54 / \mathrm{F}$ & Unknown & $\begin{array}{l}\text { COPD, CAD, HTN, } \\
\text { obesity, epilepsy }\end{array}$ & $\mathrm{N}$ & NA & NA & ND & 2 & ND & $\mathrm{N}$ \\
\hline 16 & $70 / \mathrm{F}$ & Unknown & $\begin{array}{c}\text { RA, CHF, } \\
\text { cholelithiasis }\end{array}$ & $\mathrm{Y}$ & $\mathrm{Y}$ & 72 & $\mathrm{IF} /-$ & $\begin{array}{l}1- \\
2+\end{array}$ & $\begin{array}{l}\text { S. epidermidis } \\
\text { (blood) }\end{array}$ & $\mathrm{Y}$ \\
\hline 18 & $88 / \mathrm{M}$ & 3 & CAD, CHF, HTN & $\mathrm{Y}$ & $\mathrm{Y}$ & 1 & ND & 2 & ND & $\mathrm{N}$ \\
\hline 20 & $29 / \mathrm{M}$ & 7 & $\begin{array}{l}\text { HIV, hepatitis C, } \\
\text { CAD }\end{array}$ & $\mathrm{Y}$ & $\mathrm{Y}$ & 7 & ND & 2 & - (blood) & $\mathrm{Y}$ \\
\hline Group & 3 - deat & due to ot & serious disease with $\mathrm{i}$ & enza & $\mathrm{H} 1 \mathrm{N1}$ & an a & panying 1 & & & \\
\hline 5 & $32 / \mathrm{M}$ & 16 & $\begin{array}{l}\text { HIV, generalized } \\
\text { candidiasis, ALD }\end{array}$ & $\mathrm{Y}$ & $\mathrm{Y}$ & 1 & ND & 2 & $\begin{array}{l}\text { S. aureus, En- } \\
\text { terobacter spp., } \\
\text { Prevotella spp., } \\
\text { C. glabrata } \\
\text { (postmortem) }\end{array}$ & $\mathrm{Y}$ \\
\hline $7^{*}$ & $79 / \mathrm{M}$ & 13 & CAD, acute MI & $\mathrm{Y}$ & $\mathrm{Y}$ & 10 & ELISA/+ & $\begin{array}{l}1- \\
2+\end{array}$ & - (blood) & $\mathrm{Y}$ \\
\hline 10 & $68 / \mathrm{M}$ & Unknown & $\begin{array}{c}\text { Colon carcinoma, } \\
\text { postoperative peri- } \\
\text { tonitis }\end{array}$ & $\mathrm{Y}$ & $\mathrm{Y}$ & 11 & ND & 2 & $\begin{array}{l}\text { E. coli, Capno- } \\
\text { cytophaga spp. } \\
\text { (postmortem) }\end{array}$ & $\mathrm{Y}$ \\
\hline 15 & $77 / / F$ & Unknown & $\begin{array}{l}\text { Coxal infection, } \\
\text { sepsis, CAD, DM, } \\
\text { HTN, obesity }\end{array}$ & $\mathrm{Y}$ & $\mathrm{Y}$ & 60 & ND & 2 & $\begin{array}{l}\text { Streptococcus } \\
\text { pneumoniae } \\
\text { (blood) }\end{array}$ & $\mathrm{Y}$ \\
\hline \multicolumn{11}{|c|}{ Decedents not autopsied } \\
\hline $12^{*}$ & $82 / \mathrm{M}$ & 31 & $\begin{array}{l}\text { CAD, CHD, HTN, } \\
\text { DM, peripheral } \\
\text { artery disease } \\
\end{array}$ & $\mathrm{Y}$ & $\mathrm{Y}$ & 31 & ND & 1 & $-($ blood $)$ & $\mathrm{Y}$ \\
\hline 17 & $75 / \mathrm{M}$ & 6 & Tuberculosis & $\mathrm{Y}$ & $\mathrm{N}$ & 6 & ND & 1 & ND & $\mathrm{Y}$ \\
\hline
\end{tabular}

*Received antiviral therapy.

ALD, alcoholic liver disease; CAA, chronic alcohol abuse; CAD, coronary artery disease; CHF, congestive heart failure; COPD, chronic obstructive pulmonary disease; DM, diabetes mellitus; ELISA, enzyme-linked immunosorbent assay for in vitro determination of antibodies against influenza A and B (Euroimmune, Germany); HIV, human immunodeficiency virus; HTN, hypertension; IF, direct immunofluorescence test for detection of influenza A and B (Oxoid, Denmark); MI, myocardial infarction; NA, not applicable; ND, not done; RA, rheumatoid arthritis; RIDT, rapid influenza diagnostic test (Certest Biotec, Spain); Y, yes; N, no; +, positive; - , negative. 
Table 3. Gross and Histopathological Findings of Pulmonary and Other Organ Systems of the 19 Study Decedents Who Underwent Autopsy (Cases Grouped According to the Primary Cause of Death)

Case Age,
No. Years/ Pulmonary Pathological Findings $\quad$ Pathological Findings of Other Organ Systems

Group 1 - death due to influenza or its complications (bacterial superinfection)

1 14/M Acute hemorrhagic pneumonia with DAD, pulmo- Adrenal hematoma nary edema, acute tracheitis, bronchitis, bronchiolitis, and fibrinous pleuritis

$252 / \mathrm{M}$ Acute hemorrhagic pneumonia, patchy areas of DAD Cerebral edema, grade $3 \mathrm{CAD}^{*}$ with hyaline membranes, hemorrhages and pulmonary edema, acute tracheitis, bronchitis, bronchiolitis

$1131 / \mathrm{F}$ Heavy diffuse interstitial hyperemia and edema, mild Diabetic glomerulosclerosis, 12-week pregnancy pneumonia

13 15/M Acute necrotizing bacterial pneumonia, DAD and Cerebral edema, subarachnoid hemorrhage $(2.5 \mathrm{~cm})$, acute hemorrhages, pulmonary edema, focal abscesses with hemorrhagic gastritis predominantly mononuclear infiltration. Acute tracheitis, bronchitis, bronchiolitis

$193 / \mathrm{F}$ Acute tracheitis, bronchitis, bronchiolitis, peribron- Acute septic splenitis, acute tonsillitis, acute interstitial nechitis, pulmonary edema, bilateral hemothorax phritis, cerebral edema, myocarditis with mild diffuse myocardial lymphocytic infiltration

$2150 / \mathrm{F}$ Mild acute bronchitis, focal peribronchial infiltrates Diffuse tubulonecrosis, extensive hemorrhages and interstitial edema, cerebral edema, ALD

Group 2 - death due to influenza or its complications with severe underlying disease contributing to fatal outcome

3 58/M Diffuse necrotizing bacterial pneumonia with focal Grade 4 CAD, postinfarction myocardial scarring, left venabscesses and focal organization, acute bronchitis, tricular hypertrophy, CHF $\dagger$, diabetic vasculopathy, LC bronchiolitis, and pleuritis

4 69/M Acute pneumonia with acute DAD and diffuse hya- Grade 2 CAD, patchy myocardial fibrosis, CHF, renal acute line membranes, acute bronchitis, bronchiolitis, and tubulonecrosis focal hemorrhages

6 75/M Acute hemorrhagic necrotizing pneumonia with ab- Grade 2 CAD, HTN with left ventricular hypertrophy CHF, scesses, DAD and hyaline membranes, edema, acute chronic pyelonephritis tracheitis, bronchitis, and bronchiolitis

8 68/M Organizing pneumonia with DAD, diffuse alveolar Acute hemorrhagic gastritis, HTN with left ventricular hyfibrin depositions, and macrophage infiltration pertrophy and myocardial fibrosis left ventricular dilatation, grade $1 \mathrm{CAD}, \mathrm{CHF}$

9 46/M Mild acute pneumonia with congestion and patchy Sepsis with acute hepatitis and purulent meningitis with diffuse granulocytic microinfiltrates, mild acute tracheitis cerebral edema, focal cerebral hemorrhages and granulocytic and bronchitis infiltration, granulocytic thrombi in meningeal blood vessels, purulent pericarditis and myocarditis, grade 1 CAD, LC

$1454 / \mathrm{F}$ Acute hemorrhagic pneumonia, DAD, pulmonary Chronic obstructive bronchitis, grade 2 CAD, postinfarction edema, acute tracheitis, bronchitis, and bronchiolitis myocardial scarring, CHF, HTN with splenic and renal arterial sclerosis, diffuse renal tubulonecrosis, liver steatosis

$1670 / \mathrm{F}$ Interstitial rheumatoid lung disease with focal inter- Chronic cor pulmonale with right ventricular hypertrophy, stitial and alveolar fibrosis, pulmonary edema, and myocardial fibrosis and lipomatosis, CHF with congestive microhemorrhages, acute and chronic bronchitis, liver cirrhosis, rheumatoid polyarthropathy bronchiolitis, and mild tracheitis

18 88/M Acute pneumonia with DAD, pulmonary edema, and Cerebral edema, grade 1 CAD, hypertensive heart disease intra-alveolar hemorrhages, mild acute bronchitis with left ventricular hypertrophy and myocardial fibrosis, and bronchiolitis $\mathrm{CHF}$

20 29/M Acute diffuse necrotizing pneumonia, DAD with hya- HIV, chronic hepatitis, septic splenitis, cerebral edema, line membranes, pulmonary edema, patchy hemor- chronic interstitial nephritis, acute tubulonecrosis, grade 2 rhages and subpleural abscesses with purulent pleuri- CAD tis, acute tracheitis, bronchitis, and bronchiolitis

Group 3 - death due to another serious disease with influenza A (H1N1) as an accompanying factor

5 32/M Organizing bronchopneumonia with DAD, diffuse HIV, generalized candidiasis: mycotic meningitis, mycotic alveolar fibrin deposits, diffuse mycotic infiltration, infiltrations of the lymph nodes, spleen, kidneys, heart, and focal abscesses, hemorrhages and edema, bronchitis, liver and bronchiolitis

\begin{tabular}{ccll}
\hline 7 & $79 / \mathrm{M}$ & Initial pneumonia with focal peribronchial infiltrates & $\begin{array}{l}\text { Grade } 4 \text { CAD with coronary artery thrombosis and initial } \\
\text { MI, CHF }\end{array}$ \\
\hline 10 & $68 / \mathrm{M}$ & $\begin{array}{l}\text { Diffuse necrotizing bacterial pneumonia with focal } \\
\text { abscesses and hemorrhages, acute necrotizing bron- } \\
\text { chitis, and bronchiolitis }\end{array}$ & $\begin{array}{l}\text { Colon papillary adenocarcinoma, acute intestinal ischemia } \\
\text { and dehiscence of ileotransverse anastomosis, focal intestinal } \\
\text { mucosal necrosis with initial peritonitis, grade 3 CAD, CHF }\end{array}$ \\
\hline 15 & $77 / \mathrm{F}$ & $\begin{array}{l}\text { Initial pneumonia with focal peribronchial infiltrates } \\
\text { and edema }\end{array}$ & $\begin{array}{l}\text { Acute necrotic inflammation of left hip joint, acute sep- } \\
\text { tic splenitis, cerebral edema, grade 3 CAD, HTN with left } \\
\text { ventricular hypertrophy and interstitial fibrosis, diabetic ne- } \\
\text { phropathy }\end{array}$ \\
\hline
\end{tabular}

${ }^{*}$ Coronary artery disease (CAD) was graded as follows: grade 1, thickening of a vessel wall with less than $25 \%$ narrowing of lumen; grade 2, thickening of a vessel wall with $25 \%$ to $50 \%$ narrowing of lumen; grade 3, thickening of a vessel wall with $50 \%$ to $75 \%$ narrowing of lumen; grade 4, thickening and calcification of a vessel wall with more than $75 \%$ narrowing of lumen.

$\dagger$ Congestive heart failure (CHF) was estimated as chronic venous congestion of the liver, lungs, and spleen.

ALD, alcoholic liver disease; DAD, diffuse alveolar damage; DM, diabetes mellitus, HIV, human immunodeficiency virus; HTN, hypertensive heart disease; LC, liver cirrhosis; MI, myocardial infarction. 


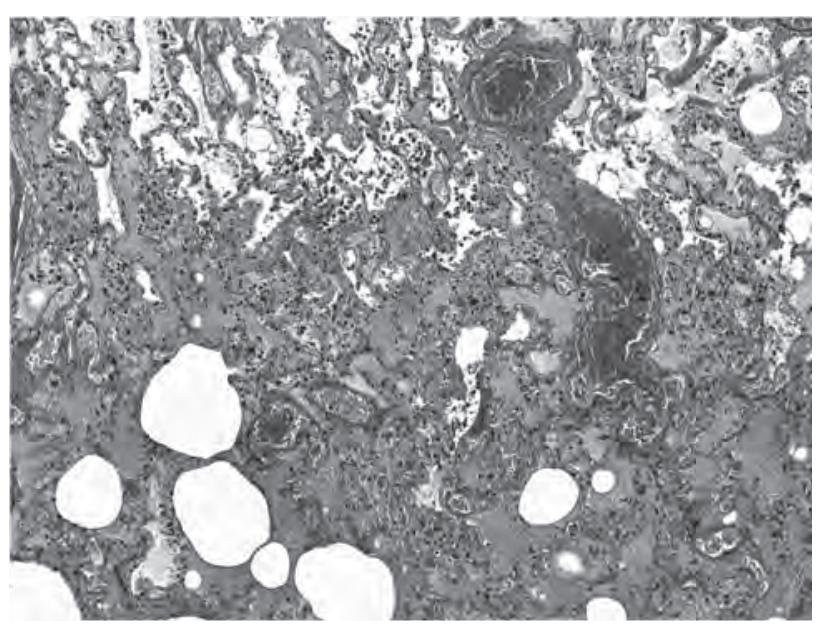

A

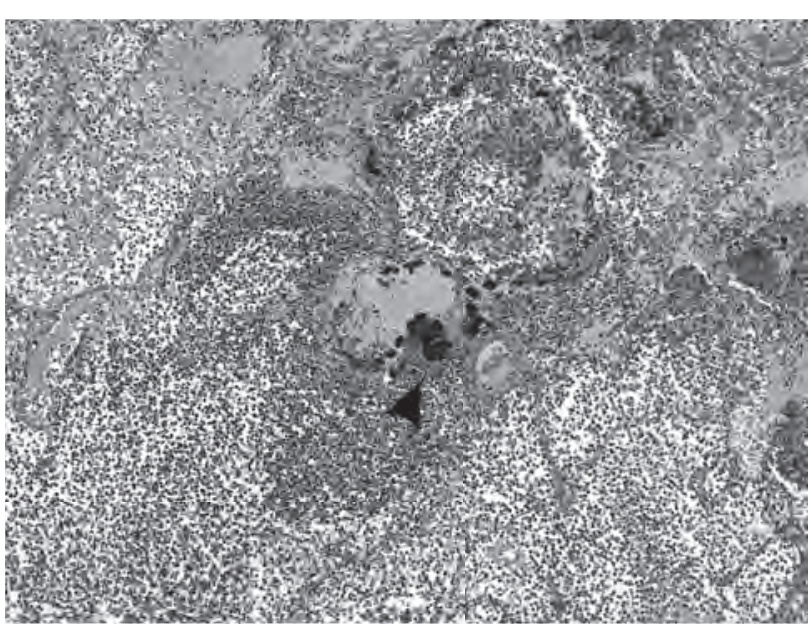

$\mathrm{B}$

Fig. 2. Histopathological changes associated with the fatal pandemic influenza A (H1N1) infection

Photomicrographs of hematoxylin-eosin stained tissue sections (original magnification $\times 100$ ). A, massive pulmonary edema and hemorrhage in early bronchopneumonia. The alveolar air spaces contain edema fluid and erythrocytes. Alveolar capillary congestion is prominent. B, extensive necrotizing alveolitis. The alveolar walls are necrotic and alveolar air spaces contain edema fluid, desquamated epithelial cells, erythrocytes, and massive neutrophils along with abscess formation. Bacterial colonies can be seen (arrowhead).

the cause of death in patient 21 .

In the group 2, all the 9 patients (median age, 37.5 years) had histopathological evidence of a severe underlying disease in addition to viral or bacterial pneumonia. Viral pulmonary lesions dominated in 5 patients, while a secondary bacterial infection in the form of necrotizing pneumonia was present in 3 patients (cases 3,6, and 20) and in the form of purulent meningoencephalitis with myocarditis and pericarditis in 1 patient (case 9). In case 16, acute pathological findings were overwhelmed by interstitial rheumatoid lung disease, and although blood culture was positive, pulmonary edema and microhemorrhages were characteristic of viral pneumonia rather than of a bacterial infection. Superinfections seemed to be more frequent in this group (4 of 9) compared with the group 1 ( 2 of 6 ), but the numbers were too small to be conclusive. The evidence of serious comorbidities included coronary artery disease (CAD) with narrowing of the lumen (grade 2-4), postinfarction myocardial scarring, hypertensive heart disease with left ventricular hypertrophy and interstitial myocardial fibrosis or hypertensive renal arterial sclerosis, evidence of congestive heart failure (chronic venous congestion of the liver, lungs, and spleen), chronic pyelonephritis, chronic obstructive bronchitis, liver cirrhosis, chronic hepatitis, diabetic systemic vascular damage, interstitial rheumatoid lung disease, and sepsis. All decedents in this group had more than one comorbidity.

In the group 3 (median age, 72.5 years), influenza A (H1N1) was clinically suspected in only 1 case; in the other 3 , it was confirmed postmortem. All these patients were critically ill due to another pri- mary disease, namely ongoing peritonitis (case 10), septic arthritis (case 15), and AIDS with the disseminated Candida glabrata infection (case 5). One patient (case 7) died due to acute myocardial infarction (MI) within 24 hours after a revascularization procedure.

\section{Discussion}

After analyzing all death cases in Estonia during the 2009-2010 A (H1N1) pandemic, the following findings deserve to be highlighted: first, almost half of the decedents were older than 65 years; second, the vast majority had significant comorbidities; third, pathological findings of lungs suggestive of influenza were observed in most cases; fourth, the usage of antiviral medications and influenza vaccines was extremely low; and, finally, after eliminating the impact of severe concomitant diseases, influenza or its complications were the sole cause of death in only one-third of cases.

In Estonia, the autopsy rate of patients dying in hospital is about 40\% (19), which is 2-5 times higher than reported in many other countries $(20,21)$. The high autopsy rate together with recommended testing for A (H1N1) in all decedents with macroscopic evidence of pneumonia allowed us to identify the cases without a clinical suspicion of influenza. Although the population mortality rate in Estonia was higher than in several other countries ( 1.56 per 100000 in Estonia vs. 0.31 per 100000 in Germany and 0.76 per 100000 in the United Kingdom) (22), these data should be treated with caution as the $95 \%$ CI are very wide. This was most likely due to the limited number of deaths in the small population of 
Estonia. Variation in attack rates among various age groups in different regions of the world and, consequently, in the health status of the affected population also explains some of the observed disparities in population mortality rates (7). Our cohort included a high proportion of the elderly in whom high disease-severity and case-fatality rates are expected $(7,8)$. Such a distribution by age contrasts with most other cohorts of pandemic A (H1N1), demonstrating the predominance of younger subjects $(3,4,23,24)$. The fact that the elderly are not susceptible to the 2009 influenza A (H1N1) infection has been explained by the data from the United Kingdom and the United States revealing crossreactional antibodies to the novel A (H1N1) virus in a substantial proportion of the cohort born before 1957 (25, 26). Animal experiments have also demonstrated that exposure to the 1934 and 1947 influenza A viruses protects against fatal challenge with the 2009 A (H1N1) virus (27). Whether the Estonian elderly do not have this protection or other reasons are involved is less clear. Unfortunately, no data are available about the prevalence of anti-influenza antibodies or about the influenza epidemics of the first half of the 20th century in the Estonian population. Still, similarly to our data, some countries have reported a median age as high as 53 to 54 years in the fatal group and a population mortality rate of 1.1 to 1.32 per 100000 (7, 28). Thus, the understanding that younger age groups were at higher risk during the recent pandemic may not be entirely true.

Bacterial superinfection has been the most common reason of death during the influenza pandemics of the 20th century, as reported in $28 \%-55 \%$ of cases in $\mathrm{A}(\mathrm{H} 1 \mathrm{~N} 1)$ fatal cohorts $(6,29)$. The question whether direct viral damage to lung parenchyma or bacterial superinfection leads to death in influenza is still controversial. Experimental studies have shown an increased mortality rate of mice infected with an influenza virus and $S$. aureus as compared with those infected with either agent alone (30). In our cohort, bacterial superinfections in lungs were observed in $40 \%$ of the patients in the group 1 (the group with A [H1N1] as a sole cause of death) suggesting that the influenza virus itself can cause significant damage in lung parenchyma leading to rapid death. This is further supported by the fact that more than half of the patients in our cohort died either at home or within the first 24 hours of hospitalization.

Pathological findings associated with lung damage, such as edema, DAD, hemorrhage, and/or inflammatory infiltration $(5,10)$, are widely accepted as suggestive of an influenza infection. The present study clearly demonstrates that the pandemic influenza infection can also proceed with only minor lung involvement, especially in patients whose status is compromised by severe underlying diseases.

Indeed, the high prevalence of serious accompanying illnesses in the elderly, as seen in our cohort, probably contributed most to high population mortality rate. The general structure of underlying conditions observed here resembles earlier studies $(8,23)$. The low rate of chronic respiratory disease $5 \%$ in our cohort compared with $20 \%-30 \%$ in others - was an exception $(8,23)$. This is even lower than the prevalence of chronic respiratory diseases among the Estonian population (31) suggesting a good control of asthma and chronic bronchitis. However, for patients with chronic heart disease as the most frequent comorbidity in our fatal group, routine vaccination against influenza should be strongly recommended.

It is important to emphasize that none of our pediatric patients had significant chronic illnesses. This contrasts with the data about adults as well as other pediatric series (32). Our data, although small in numbers, suggest that in Estonia immunizations against influenza should be given to all children and not only to groups at risk.

Another issue in our cohort was a much lower use of neuraminidase inhibitors compared with other studies $(8,23)$ despite the fact that their efficacy in the treatment of severe influenza is proven (33) and that their liberal use in ambulatory settings has been associated with reduced mortality during the 2009 pandemic $(8,34)$. The reasons for the low rate of antiviral use may include no suspicion of influenza (especially in critically ill patients in the ICU), low intravital influenza testing rate, belief that neuraminidase inhibitors are effective only if given within 48 hours from the onset of symptoms as indicated in the Summary of Product Characteristics (35), fear of shortage of drug supply, and a high proportion of early deaths in the cohort. The risk of emerging resistance to neuraminidase inhibitors may also have contributed, although the reported rate of oseltamivir-resistant 2009 A (H1N1) viruses has remained below $2 \%(36,37)$. Based on these data, early more liberal use of antiviral medications is advocated still bearing in mind the hazard of resistance.

Already prior to the recent influenza pandemic, the unpopularity of influenza immunizations in Estonia was one of the greatest in Europe with only $1.1 \%$ vaccinated (38), and this did not change in 2009-2010. Although free immunizations were offered first to groups at risk and then to the whole population, only $2.3 \%$ of the population received the pandemic vaccine (11). This rate is almost 4 times lower than the European average (39). Thus, not surprisingly, none of the decedents were immunized, which may have played some role in the high 
mortality as effectiveness of influenza immunization has been demonstrated in several studies $(40,41)$.

In our opinion, several issues should be taken into consideration in a retrospective analysis. First, the number of cases was relatively small. However, it involved the entire national cohort of the influenza A (H1N1) decedents allowing us to describe the outcomes for the whole population handled according to the nationwide guidelines during the epidemic. Missing data as a common problem in retrospective analyses have likely not affected our results as the present study focuses on the pathological findings, and histological slides were available for review in all autopsied cases.

\section{Conclusions}

The high autopsy rate and liberal postmortem PCR testing enables the detection of additional influenza A (H1N1) cases, yet it may lead to overestimation of the population mortality rates due to influenza, especially in a small population with

\section{References}

1. Garten RJ, Davis CT, Russell CA, Shu B, Lindstrom S, Balish A, et al. Antigenic and genetic characteristics of swineorigin $2009 \mathrm{~A}(\mathrm{H} 1 \mathrm{~N} 1)$ influenza viruses circulating in humans. Science 2009;325:197-201.

2. CDC. Update: novel influenza A (H1N1) virus infections worldwide, May 6, 2009. MMWR Morb Mortal Wkly 2009; 58:453-8.

3. Vaillant L, La Ruche G, Tarantola A, Barboza P. Epidemiology of fatal cases associated with pandemic H1N1 influenza 2009. Euro Surveill 2009;14(33). pii: 19309.

4. Louie JK, Acosta M, Winter K, Jean C, Gavali S, Schechter $\mathrm{R}$, et al. Factors associated with death or hospitalization due to pandemic 2009 influenza $\mathrm{A}(\mathrm{H} 1 \mathrm{~N} 1)$ infection in California. JAMA 2009;302:1896-902.

5. Mauad T, Hajiar LA, Callegari GD, da Silva LF, Schout D, Galas FR, et al. Lung pathology in fatal novel human influenza A (H1N1) infection. Am J Respir Crit Care Med 2010;181:72-9.

6. Gill JR, Sheng ZM, Ely SF, Guinee DG, Beasley MB, Suh J, et al. Pulmonary pathologic findings of fatal 2009 pandemic influenza A/H1N1 viral infections. Arch Pathol Lab Med 2010;134:235-43.

7. Helferty M, Vachon J, Tarasuk J, Rodin R, Spika J, Pelletier L. Incidence of hospital admissions and severe outcomes during the first and second waves of pandemic (H1N1) 2009. CMAJ 2010;182:1981-7.

8. Yang P, Deng Y, Pang X, Shi W, Li X, Tian L, et al. Severe, critical and fatal cases of $2009 \mathrm{H} 1 \mathrm{~N} 1$ influenza in China. J Infect 2010;61:277-83.

9. Rosen DG, Lopez AE, Anzalone ML, Wolf DA, Derrick SM, Florez LF, et al. Postmortem findings in eight cases of influenza A/H1N1. Mod Pathol 2010;23:1449-57.

10. Taubenberger JK, Morens DM. The pathology of influenza virus infections. Annu Rev Pathol 2008;3:499-522.

11. Kutsar K. A(H1N1) 2009 gripipandeemia maailmas ja Eestis. (A(H1N1) 2009 influenza pandemics in the world and in Estonia.) Eesti Arst 2010;89:620-5.

12. Republic of Estonia. Surma põhjuse tuvastamise seadus. (Establishing Cause of Death Act.) [cited 2010 Nov 16]; Available from: URL: https://www.riigiteataia.ee/akt/895466

13. Statistics Estonia. Autopsy rate by sex and cause of death [cited 2010 Nov 26]; Available from: URL: http://pub.stat. low number of events. Still, it may be stated that in Estonia increased vaccine coverage (especially of risk groups), vigilant intravital diagnosing including wide PCR testing, and early more liberal use of antiviral medications during the influenza A (H1N1) epidemic may hold the potential of lowering population mortality.

\section{Acknowledgments}

The authors would like to thank East-Tallinn Central Hospital, Ida-Viru Central Hospital, Narva Hospital, North Estonian Regional Hospital, Tartu University Hospital, Pärnu Hospital, West-Tallinn Central Hospital, and the Estonian Health Board for their cooperation in the project and Dr. Marje Oona for her careful reading of the manuscript.

The study was funded by the Health Board of Estonia.

\section{Statement of Conflict of Interest}

The authors state no conflict of interest.

ee/px-web.2001/I Databas/Population/databasetree.asp

14. International statistical classification of diseases and related health problems 10th revision version for 2007. [cited 2010 Nov 26]; Available from: URL: http://www.who.int/classifi cations/icd/en/

15. Statistics Estonia. Population indicators and composition. [cited 2010 Nov 26]; Available from: URL: http://pub.stat. ee/px-web.2001/dialog/statfile1.asp

16. Confidence intervals in public health. [cited 2011 Dec 9]; Available from: URL: http://health.utah.gov/opha/IBI Shelp/ ConfInts.pdf

17. World Health Organization. CDC protocol or realtime RTPCR for influenza A(H1N1). [cited 2010 Nov 12]; Available from: URL: http://www.who.int/csr/resources pub lications/swineflu/CDCRealtimeRTPCR SwineH1Assay2009 20090430.pdf

18. National Committee for Clinical Laboratory Standards. Methods for dilution antimicrobial susceptibility tests for bacteria that grow aerobically. Approved Standard. 6th ed. 2003;20(2).

19. Jõeste E. Patoloogia areng tänases Eesti meditsiinis. (Pathology today in Estonia.) Eesti Arst 2002;81:269-74.

20. Autopsy. A comprehensive review of current issues. Council on Scientific Affairs. JAMA 1987;258:364-9.

21. The Royal College of Pathologists of Autralasia Autopsy Working Party. The decline of the hospital autopsy: a safety and quality issue for healthcare in Australia. Med J Aust 2004;180:281-5.

22. ECDC. 2009 influenza A (H1N1) pandemic: epidemiological data: number of fatal cases 2010 [cited 2011 Dec 9]; Available from: URL: http://ecdc.europa.eu/en/healthtopics/H1N1/epidemiological data/Pages/number confirmed fatal 2009 pandemic influenza cases.aspx

23. Lee EH, Wu C, Lee EU, Stoute A, Hanson H, Cook HA, et al. Fatalities associated with the 2009 H1N1 influenza A virus in New York city. Clin Infect Dis 2010;50:1498-504.

24. Kumar A, Zarychanski R, Pinto R, Cook DJ, Marshall J, Lacroix J, et al. Critically ill patients with 2009 influenza A(H1N1) infection in Canada. JAMA 2009;302:1872-9.

25. Miller E, Hoschler K, Hardelid P, Stanford E, Andrews N, Zambon M. Incidence of 2009 pandemic influenza A H1N1 infection in England: a cross-sectional serological study. 
Lancet 2010;375:1100-8.

26. CDC. Serum cross-reactive antibody response to a novel influenza A (H1N1) virus after vaccination with seasonal influenza vaccine. MMWR Morb Mortal Wkly Rep 2009; 58:521-4.

27. Skountzou I, Koutsonanos DG, Kim JH, Powers R, Satyabhama L, Masseoud F, et al. Immunity to pre-1950 H1N1 influenza viruses confers cross-protection against the pandemic swine-origin 2009 A (H1N1) influenza virus. J Immunol 2010;185:1642-9.

28. Athanasiou M, Lytras T, Spala G, Triantafyllou E, Gkolfinopoulou K, Theocharopoulos G, et al. Fatal cases associated with pandemic influenza A (H1N1) reported in Greece. PLoS Curr [serial online] 2010; 2 RRN1194. [cited 2010 Nov 24]; Available from: URL: http://www.ncbi.nlm.nih. gov/entrez/query.fcgi? $\mathrm{cmd}=$ Retrieve\& $\mathrm{db}=$ PubMed\&dopt $=$ Citation\&list uids $=21085493$

29. Morens DM, Taubenberger JK, Fauci AS. Predominant role of bacterial pneumonia as a cause of death in pandemic influenza: implications for pandemic influenza preparedness. I Infect Dis 2008;198:962-70.

30. Lee MH, Arrecubieta C, Martin FJ, Prince A, Borczuk AC, Lowy FD. A postinfluenza model of Staphylococcus aureus pneumonia. J Infect Dis 2010;201:508-15.

31. Jannus-Pruljan L, Meren M, Polluste J, Loit HM, Kiviloog J, Baburin A, et al. Postal survey on asthma, chronic bronchitis and respiratory symptoms among adult Estonians and non-Estonians (FinEsS-study). Eur J Public Health 2004; $14: 114-9$

32. Sachedina N, Donaldson LJ. Paediatric mortality related to pandemic influenza A H1N1 infection in England: an observational population-based study. Lancet 2010;376:184652.

33. Burch J, Corbett M, Stock C, Nicholson K, Elliot AJ, Duffy $S$, et al. Prescription of anti-influenza drugs for healthy adults: a systematic review and meta-analysis. Lancet Infect
Dis 2009;9:537-45

34. Goldstein E, Lipsitch M. Antiviral usage for H1N1 treatment: pros, cons and an argument for broader prescribing guidelines in the United States. PLoS Curr 2009;1:RNN1122. Available from: URL: http://www.ncbi.nlm.nih.gov/entrez/ query.fcgi $? \mathrm{cmd}=$ Retrieve $\& \mathrm{db}=$ PubMed $\& \mathrm{dopt}=$ Citation $\&$ li st uids $=20029660$

35. Tamiflu. Summary of product characteristics. [cited 2010 Nov 24]; Available from: URL: http://ec.europa.eu/health/ documents/community-register/2010/2010070281568/ anx 81568 en.pdf

36. WHO. Weekly epidemiological record. Weekly epidemiological record [serial online] 2010;85(6):37-48. [cited 2010 Nov 16]; Available from: URL: http://www.who.int/ wer/2010/wer8506.pdf

37. Duwe SC, Wedde M, Birkner P, Schweiger B. Genotypic and phenotypic resistance of pandemic A/H1N1 influenza viruses circulating in Germany. Antiviral Res 2010;89:1158.

38. Mereckiene J, Cotter S, D’Ancona F, Giambi C, Nicoll A, Levy-Bruhl D, et al. Differences in national influenza vaccination policies across the European Union, Norway and Iceland 2008-2009. Euro Surveill 2010;15(44). pii: 19700.

39. ECDC. The $2009 \mathrm{~A}(\mathrm{H} 1 \mathrm{N1})$ pandemic in Europe. [cited 2010 Nov 16]; Available from: URL: http://www.ecdc.europa.eu/en/publications/Publications/101108 SPR pandemic_experience.pdf

40. Frey S, Vesikari T, Szymczakiewicz-Multanowska A, Lattanzi M, Izu A, Groth N, et al. Clinical efficacy of cell culture-derived and egg-derived inactivated subunit influenza vaccines in healthy adults. Clin Infect Dis 2010;51:9971004.

41. Bracco Neto H, Farhat CK, Tregnaghi MW, Madhi SA, Razmpour A, Palladino G, et al. Efficacy and safety of 1 and 2 doses of live attenuated influenza vaccine in vaccine-naive children. Pediatr Infect Dis J 2009;28:365-71. 